\title{
Assessing the Radiological Progression of Simple Pneumoconiosis
}

\author{
P. D. OLDHAM
}

\author{
From the Pneumoconiosis Research Unit, Llandough Hospital, Penarth, Glamorgan
}

The Medical Service of the National Coal Board has recently issued the fourth in a series of medical research memoranda, in which the results of studies carried out on various aspects of the health of men working in this large industry are made generally available (Liddell and May, 1966). This memorandum is concerned with the technical aspects of what seems at first a simple matterdetecting and measuring increases in the amount of abnormality attributed to simple pneumoconiosis in the chest radiographs of coalminers.

Simple pneumoconiosis is classified under the International Labour Organization (I.L.O.) system into four categories of increasing profusion of small opacities. The uncountable number of visible small opacities forms a continuum of abnormality, and the progression which is to be detected, whatever its significance, is an increase in this number. Sometimes progression produces a change of category, when the increased number of opacities takes the film across a category boundary; sometimes an equal increase of the number of opacities leaves the category unchanged, the progression being entirely within the boundaries of the original category. Thus the number of changes of category seen, when a group of men is x-rayed on two occasions some years apart, is not necessarily a sufficient index of the amount of progression. It may depend too much on how the men's radiographs were distributed along the continuum of abnormality on the first occasion, in particular on the proportion of films showing virtually no small opacities at all. A major improvement in an index of this kind was effected by Liddell's (1963) discovery that readers of radiographs could easily indicate for each film read whether the I.L.O. category above or below the one finally chosen had been considered as a serious alternative. In this way the 4-point scale of the I.L.O. classification was effectively turned into a 12-point scale, on which the number of steps taken by each man could form an index which would respond more closely to increases in the number of opacities in the man's film.

The present memorandum is concerned primarily with an index of this sort and how its performance varied with two distinct ways of classifying the

Received for publication August 18, 1967. films. In one, the two films of each man are examined simultaneously ('side-by-side' reading). Each is separately classified on the elaborated scale of categories, but allowance can be made for special features of the two, such as a difference in radiographic technique or of positioning. In the other, the first and second films of all the men are mixed into one series, so that each film is classified quite independently of the other film of the same man. The resulting indices of progression were examined for their ability to discriminate between different colliery populations, their repeatability from one observer to another, their correlation with the estimated dust exposures of individuals, and their ability to give near-zero values when applied to films actually taken on the same occasion. Several series of films were used in the study, several sets of readers, and the elaborated and original I.L.O. classifications, all in conjunction with the various indices under test, so that the numerous tables require careful study before their implications can be appreciated. An excellent glossary of the abbreviations and technical terms adopted makes this much easier than it might otherwise be.

The possible applications of the results in practice are discussed in several places in the monograph. One application is clearly set first; this is to find the best method of providing an index of progression for whole colliery populations, so that those populations which have been exposed to unacceptable concentrations of respirable airborne dust may be distinguished. For this purpose the authors conclude that side-by-side reading of the pairs of films, each being classified on the elaborated I.L.O. system, is the best. The index chosen is then an average over the whole population, and over pairs of readers, of the number of steps on the elaborated classification. In every case the elaborated classification produced better results than the simple I.L.O. classification, so providing new evidence of the value of Liddell's original proposal of this system. The advantage claimed for side-by side reading over separate reading seems less certain.

An essential point is to recognize that the conclusions reached by the authors are restricted, as the full title of the monograph suggests, to the particular purposes of the Periodic $X$-ray Scheme of the Board. The conclusions are relevant to the main 
practical problem with which they are faced-to find a means of ranking collieries according to the progression of their whole working populations. However, for purposes such as the establishment of a relationship between exposure to dust and progression of pneumoconiosis in the individual, comparison of progression over one interval with progression over another, comparison of progression in British coalmines with progression in other dusty industries or in mines in other countries-for such purposes the conclusions of the present memorandum are not necessarily to be accepted.

The authors comment that little has previously been published on assessment of the progression of simple pneumoconiosis. It is notable that such work as has been published has presented conclusions for general purposes directly opposed to those now reached. Wise and Oldham (1963) concluded that side-by-side reading led to gross underestimates of progression. That finding is now attributed to the fact that these authors used readings which had been obtained by pairs of observers working together, though it is not clear why this procedure should lead to a bias in reading a man's films sideby-side but not in reading them singly. In fact, the effect was quite markedly present in the results now reported, and it seems that it has been discounted because of the considerably larger variation between observers found in the separate readings. Moreover, some data from an internal National Coal Board report by Ashford, Pearson, Morgan, and Pasqual are cited, which show lower measures of progression by side-by-side reading in six out of eight groups; this effect is said to be not sufficiently marked to warrant outright rejection of this method of reading on these grounds alone, and the weight of this conflicting evidence is not further considered. The authors remark, on page 16 of the report, that they would regard with suspicion any method of reading which produced levels of progression markedly different from those obtained by reading the films separately. The recording of lower levels of progression by side-by-side reading, in a fairly consistent way, might be thought worthy of such suspicion, however large or small the difference. It is not reassuring to think that a system which might tend to underestimate true progression had been adopted, even provisionally, for the routine surveillance of colliery populations.

A second conclusion by Wise and Oldham is not discussed; this is that the same amount of progression is not found at all points of the continuum of simple pneumoconiosis. If this were confirmed it would be highly relevant to the comparison of progression in one colliery population with progression in another; it might be that unless the 6 proportions of men in different categories of pneumoconiosis were similar the amount of progression, even in similar dust conditions, would vary. The device of percentile pairing suggested by Wise and Oldham, which should enable even such a complex pattern of progression to be presented in a compact form, is dismissed as inevitably producing a greater problem in communicating with management and men. Whether or not this is so, it should be remembered that the central difficulty in assessing progression lies in the conflict between the continuous nature of the radiographic changes and the coarsely grouped scale on which they are recorded. Liddell's subdivision of the categories must reduce this difficulty but may not eliminate it. Recovery of a continuous measure of progression by some means (of which percentile pairing was but one suggested by Wise and Oldham) was the basic problem according to these authors.

It seems a pity that such rival claims should not have received closer attention; certainly no attempt has been made to show how well or ill they are substantiated when tested on material obtained from these studies, which were evidently conducted with great care. Nor is it easily possible for interested persons to test them for themselves, for, although the results are presented in great detail (there are some 80 tables in the appendices alone), the basic data, which are pairs of readings, are nowhere given (though they are available on punched cards for bona fide research workers).

The absence from the memorandum of any data in the basic form, of a reading on the I.L.O. or elaborated scale, provokes further speculation. How closely were the readers adhering to the actual categories of the I.L.O. scale? Were the I.L.O. standard films used for comparison? It is possible that the externally defined standards are supplanted when pairs of films are being directly compared with each other, so that greater repeatability is achieved by side-by-side reading at the expense of adherence to the international classification. The supposition is that the average reading level of the observers would accord with this external standard, but some evidence that this was so could surely have been provided. Was it evident that the distributions of the actual readings of the observers were always simply displaced with respect to each other and to their readings of other films of the men, or was there a tendency for the differences to vary with the categories read? In the first case, the average progressions and the average differences between observers used in the report would be valid and informative; in the second, they could be misleading, and more subtle analysis would be required. 
It is to be hoped that further exploration of the data will continue, and that this monograph will not constitute the authors' final words on what is to be learnt from the study they have carried out so carefully.

\section{REFERENCES}

Liddell, F. D. K. (1963). An experiment in film reading. Brit. F. industr. Med., 20, 300-312.
- and May, Joan D. (1966). Assessing the Radiological Progression of Simple Pneumoconiosis. National Coal Board Medical Service (Medical Research Memorandum 4).

Wise, M. E., and Oldham, P. D. (1963). Estimating progression of coal-workers' simple pneumoconiosis from readings of radiological categories. Brit. $\mathcal{F}$. industr. Med., 20, 124-144.

\title{
Effect of 2,3-Dimercaptopropanol (BAL) on Urinary Excretion and Brain Content of Mercury
}

\author{
L. MAGOS \\ From the Toxicology Research Unit, M.R.C. Laboratories, Carshalton, Surrey
}

2,3-Dimercaptopropanol (BAL) given to rats in doses used for the treatment of acute mercury chloride poisoning in man increases the excretion of mercury. The mercury content of the brain was unaffected by 2,3-dimercaptopropanol unless it was given a short time after the mercuric chloride, when there was a $24 \%$ increase. The relevance of these findings to therapy with BAL is discussed.

2,3-Dimercaptopropanol (BAL) treatment of acute poisoning by mercury salts is sometimes regarded as contraindicated on the grounds that in certain circumstances it did not increase mercury excretion (Fitzsimmons and Kozelka, 1950; Berlin and Lewander, 1965) and did increase the concentration of mercury in the brain (Berlin and Lewander, 1965). In this paper I show that in rats therapeutic doses (recommended by the Extra Pharmacopoeia Martindale, 1967) increased mercury excretion and, unless given very shortly after the injection of mercuric chloride, did not increase the mercury content of the brain. The previous findings are wholly explicable by the use of doses lower than those used in man and by the timing of the therapy.

\section{Materials and Methods}

Female albino rats, Porton Wistar strain, of 200-240 g. body weight, were injected, intramuscularly into one thigh, with roo $\mu \mathrm{g}$. mercury as mercuric chloride labelled with ${ }^{203} \mathrm{Hg}$ to a specific activity of 3.5 or $7.5 \mu \mathrm{C} / \mathrm{mg}$. (Radiochemical Centre, Amersham, Bucks). BAL (Boots Pure Drug Co.) in $0.1 \mathrm{ml}$. arachis oil was given intramuscularly into the other thigh. When the urine and faeces were collected the animals were placed in metabolism cages. The animals were

Received for publication September I, 1967. killed by decapitation. The mercury content of the urine, faeces, and brain was estimated by counting ${ }^{203} \mathrm{Hg}$ with an automatic scintillation spectrometer (Model 50A, Packard Instrument $\mathrm{Co}$.) having a counting efficiency of $40 \%$.

\section{Results}

When BAL was given to rats six days after the administration of mercuric chloride a dose of 2 $\mathrm{mg} . / \mathrm{kg}$. had no effect on the urinary excretion of mercury, but doses of 8 and $16 \mathrm{mg} . / \mathrm{kg}$. markedly increased it. BAL in doses of $4 \mathrm{mg} . / \mathrm{kg}$. had a marginal effect on urinary excretion. The faecal excretion remained unchanged except after the highest dose which slightly increased it (Figure).

Table I shows that doses of 6 and $16 \mathrm{mg}$. $/ \mathrm{kg}$. given five days after the administration of mercuric chloride increased the urinary excretion but had no effect on the mercury content of the brain in the animals killed $24 \mathrm{hrs}$ after the injection of BAL.

However, when BAL $(6 \mathrm{mg}$. $/ \mathrm{kg}$.) was given 90 min. after the mercuric chloride and the treatment was repeated $5,25,30$, and $48 \mathrm{hrs}$ later there was an increase in the mercury content of the brain in the animals killed 24, 48, and 72 hrs after the first injection. Table II shows that the increase in the brain mercury content was only about $24 \%$ but the urinary excretion of mercury was 2.5 times higher in the BAL-treated than in the control animals. 